\title{
COMISSÃO INTERGESTORES REGIONAL: ESPAÇO LOCAL DE PACTUAÇÃO E ARTICULAÇÃO INTERFEDERATIVA?
}

\section{ARTIGO ORIGINAL}

SANTOS, Nadja Romeiro dos ${ }^{1}$, COTA, Ana Lídia Soares²

SANTOS, Nadja Romeiro dos. COTA, Ana Lídia Soares. Comissão intergestores regional: espaço local de pactuação e articulação interfederativa? Revista Científica Multidisciplinar Núcleo do Conhecimento. Ano 06, Ed. 09, Vol. 03, pp. 173189. Setembro de 2021. ISSN: 2448-0959, Link de acesso: https://www.nucleodoconhecimento.com.br/tecnologia/comissao-intergestores-

regional, DOI: 10.32749/nucleodoconhecimento.com.br/tecnologia/comissaointergestores-regional

\section{RESUMO}

A Comissão Intergestores Regional (CIR), configura o espaço de pactuação, articulação, cooperação e fortalecimento da região de saúde. O objetivo deste estudo foi refletir sobre os dispositivos normativos que fundamentam a construção da comissão como local de consolidação de gestão regional atenuante dos conflitos interfederativos. Tendo como pergunta norteadora: de que maneira as Comissões Intergestores Regional proporcionam espaços locais de pactuação e articulação interfederativa? Estudo qualitativo, com base em pesquisa documental, a partir da análise das resoluções das Comissões Intergestores Regionais de Alagoas, correspondente ao período de 2017 a 2019, utilizando-se o Decreto 7.508/11 como padrão de referência. Os resultados foram organizados em quatro categorias: Planejamento regional em saúde; organização das ações e serviços de atenção à saúde: região de saúde; Federalismo, CIR e o financiamento dos serviços de saúde;

\footnotetext{
${ }^{1}$ Doutoranda do Programa de Pós-Graduação em Sociedade, Tecnologias e Políticas Públicas. Centro Universitário Tiradentes (UNIT).

${ }^{2}$ Doutora em Odontopediatria, Professora do Curso de Odontologia e do Programa de Pós-Graduação em Sociedade, Tecnologias e Políticas Públicas (UNIT/AL) Centro Universitário Tiradentes.
}

RC: 97046

Disponível em: https://www.nucleodoconhecimento.com.br/tecnologia/comissaointergestores-regional 
governança e as CIR: canal de negociação e decisão entre gestores municipais e o Estado no âmbito da Região de Saúde. As Comissões Intergestores Regionais desenvolvem um trabalho significativo nas discussões das políticas regionais, sendo ferramenta fundamental para o fortalecimento da governança nos territórios, pela negociação da alocação e distribuição de recursos, imprescindível para o planejamento, os pactos interfederativos, e o financiamento em saúde, desempenhando um papel de fundamental importância para o sistema regional de saúde de Alagoas, como espaço democrático, político e cooperativo.

Descritores: Regionalização, Gestão em Saúde, Sistema Único de Saúde, Federalismo, Política de Saúde.

\section{INTRODUÇÃO}

As Políticas de Saúde do Brasil têm sido formuladas visando cumprir o que determina o artigo 196 da Constituição Federal (CF/1988), a partir de ações e serviços públicos de saúde que integram uma rede regionalizada e hierarquizada, constituindo um sistema único (SUS), organizado de acordo com diversas diretrizes, dentre elas descentralização, o atendimento integral e a participação da comunidade (artigo 198) (BRASIL, 1988).

Um grande avanço neste sentido foi a regulamentação da Lei Orgânica da Saúde (Lei 8.080/90) por meio do Decreto Federal № 7.508 publicado em julho de 2011 considerado o marco normativo densificador dos dispositivos constitucionais e legais relativos à efetivação do direito fundamental à saúde no Brasil, notadamente no que tange à descentralização da saúde pública, dispondo sobre a organização do SUS, o planejamento das ações assistenciais em saúde e a articulação interfederativa.

Uma das principais conquistas refere-se à operacionalização do SUS no âmbito do território regional, a partir da validação dos espaços de pactuação e deliberação, com vistas à definição de regras de gestão compartilhada, denominadas Comissões Intergestores Regionais (CIR), sendo processo de descentralização da saúde 
pública, uma das premissas constitucionais, se intensifica com a legitimação dos espaços regionais de pactuação.

Esse processo político-administrativa do SUS no Brasil, modelo vitorioso na Assembleia Nacional Constituinte (1986-1988), foi o consectário de um dos principais pleitos do Movimento pela Reforma Sanitária, edificada em virtude das várias críticas ao modelo centralizador então vigente no país, executado, à época, pelo Instituto Nacional de Assistência Médica da Previdência Social (INAMPS).

Referido princípio organizativo também foi incorporado às outras políticas públicas instituídas, especialmente à saúde, educação e assistência social, que, em mútua articulação, estruturam as bases de um Estado de proteção social.

Segundo Wagner (2006), a descentralização tende a produzir uma autonomia decisória em relação à saúde para os entes federados. A crescente centralização financeira do Estado, ao lado do exercício continuado de regulação fiscal dos Estados e Municípios, e um papel decisivo na formulação de políticas produziram uma combinação de centralização estatal, com políticas setoriais descentralizadoras que, no caso da saúde, estiveram sempre na dependência da indução federal (VIANA et al, 2002).

Entende-se região como sendo o espaço geográfico contínuo, formado por agrupamentos de municípios limítrofes, definido a partir da existência de identidades culturais, sociais e econômicas e outros, objetivando integrar, organizar, planejar e executar ações e serviços de saúde (BRASIL, 2011).

É neste ambiente, que as CIR se destacam como instrumentos de apoio à efetivação das políticas de saúde nas regiões federativas. Na prática, funcionam como instâncias de governanças regionais das redes de atenção à saúde, cuja atuação é relevante para efetivar a dinâmica da regionalização, identificar problemas, definir prioridades e propor soluções para sua organização, auxiliando na constituição de objetivos compartilhados e no estabelecimento de uma lógica voltada para o bem-estar da população e na provisão dos serviços de saúde.

RC: 97046

Disponível em: https://www.nucleodoconhecimento.com.br/tecnologia/comissaointergestores-regional 
É no contexto de manutenção do protagonismo municipal, e de fortalecimento das relações de interdependência e corresponsabilidade sanitária entre os entes estadual e municipais, que surgem as CIR, tendo por missão a gerência da Política Regional de Saúde, a partir do conhecimento da realidade epidemiológica e socioeconômica dos municípios limítrofes.

No que tange ao estado de Alagoas, as CIR coordenam a construção da Rede de Atenção Regional (RAR), garantindo o acesso da população aos serviços de saúde regulando, monitorando e avaliando as metas estabelecidas para os municípios inseridos em sua área.

Portanto, este artigo tem como objetivo refletir sobre os dispositivos normativos que fundamentam a construção das CIR como espaços de consolidação de gestão regional atenuantes dos conflitos interfederativos, analisando a regionalização no SUS, buscando verificar a influência da cooperação intergovernamental no fortalecimento desta estratégia. Para embasar a análise proposta, foram revisados referenciais teóricos sobre o tema, partindo da visão geral dos fundamentos do federalismo, o SUS na estrutura federativa brasileira, e os conceitos de descentralização e regionalização, finalizando com a discussão de alguns fatores críticos. Diante das reflexões acima expostas, surgiu a seguinte indagação: de que maneira as CIR proporcionam espaços locais de pactuação e articulação interfederativa?

\section{METODOLOGIA}

Trata-se de um estudo descritivo e exploratório com abordagem qualitativa, realizado por meio de revisão e análise temática de conteúdo dos documentos oficiais próprios da CIR/AL, como espaço de pactuação e articulação interfederativa do SUS, permitindo agregar conhecimentos sobre o objeto estudado, analisando também, o avanço das políticas públicas de saúde a partir do processo de regionalização (MINAYO, 2010). 
Foram analisadas as resoluções elaboradas pelas $\mathrm{CIR}$, correspondentes ao período de 2017 a 2019, disponíveis ao público na página do Diário Oficial do Estado de Alagoas (DOE/AL) http://www.imprensaoficial.com.br/diario-oficial, utilizando-se o Decreto 7.508/11 como padrão de referência. Os achados foram sistematizados em quatro categorias analíticas, agrupadas após a leitura dos documentos, cujas constatações estão dispostas no quadro 1, a saber: planejamento (Categoria 1); organização (Categoria 2); financiamento (Categoria 3) e governança (Categoria 4).

\section{RESULTADOS}

Do total de 192 resoluções lidas, foi gerado um quadro analítico (Quadro 1), que ordenou os as principais deliberações da CIR e seu respectivo sentido, como conteúdos relevantes das categorias previamente eleitas, para orientar a discussão.

Quadro I: Caracterização das resoluções por categorias de análise referentes ao período de 2017-2019.

\begin{tabular}{|c|c|c|}
\hline Categoria & $\begin{array}{ll}\text { Sentido } & \text { da } \\
\text { Deliberação } & \end{array}$ & Principais Deliberações \\
\hline \multirow[t]{4}{*}{ Planejamento } & $\begin{array}{l}\text { Estratégias de } \\
\text { cooperação } \\
\text { contribuindo para a } \\
\text { pactuação, }\end{array}$ & $\begin{array}{l}\text { Aprova metas propostas pelas áreas } \\
\text { técnicas da Secretaria de Estado da Saúde } \\
\text { - SESAU referente aos Indicadores } \\
\text { interfederativos para o período 2017-2021 }\end{array}$ \\
\hline & $\begin{array}{l}\text { garantindo acesso } \\
\text { aos serviços de } \\
\text { saúde a população. }\end{array}$ & $\begin{array}{l}\text { Aprova Planejamento da Saúde, a } \\
\text { assistência à saúde e a articulação } \\
\text { interfederativa }\end{array}$ \\
\hline & $\begin{array}{lr}\text { Estratégia } & \text { que } \\
\text { favorece } & \text { a } \\
\text { qualidade } & \text { à } \\
\text { implementação } & \text { das }\end{array}$ & $\begin{array}{l}\text { Aprova Plano Estadual de Humanização } \\
\text { da Saúde do Estado de Alagoas, } \\
\text { quadriênio } 2016 \text { - } 2019 \text { e o Plano } \\
\text { Operativo } 2017\end{array}$ \\
\hline & políticas de saúde. & $\begin{array}{l}\text { Repactua metas dos Indicadores } \\
\text { Interfederativos. }\end{array}$ \\
\hline
\end{tabular}




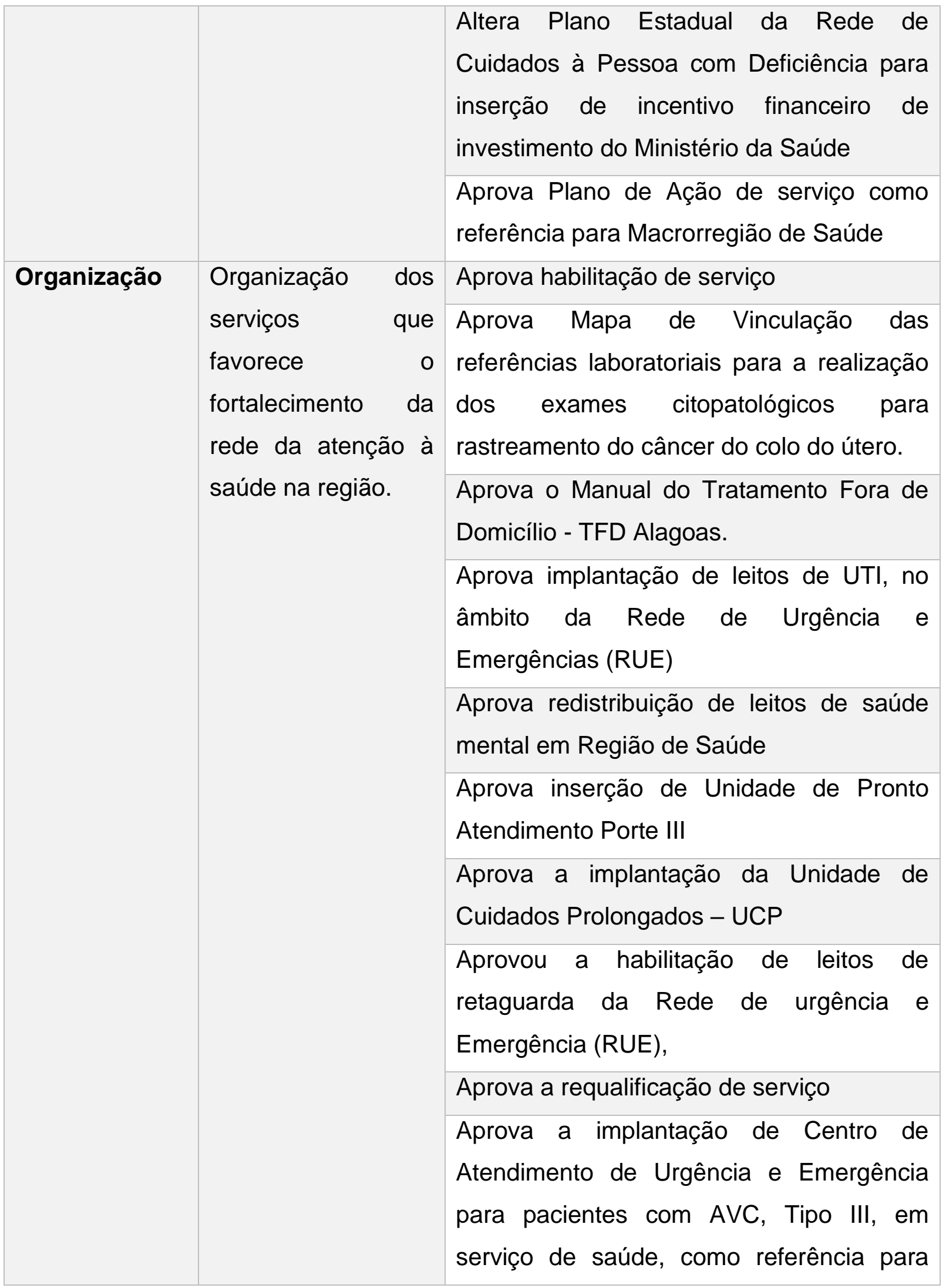




\begin{tabular}{|c|c|c|}
\hline \multirow{8}{*}{ Financiamento } & \multirow{8}{*}{$\begin{array}{lr}\text { Estratégia para } \\
\text { financiamento } \\
\text { incentivo } \\
\text { regionalização. } \\
\text { Implementação das } \\
\text { políticas públicas na } \\
\text { região. }\end{array}$} & \multirow{2}{*}{$\begin{array}{l}\text { Região de Saúde } \\
\text { Aprova a alteração da especialidade da } \\
\text { Porta de Entrada de Urgência Clínica } \\
\text { serviço. }\end{array}$} \\
\hline & & \\
\hline & & $\begin{array}{l}\text { Aprova remanejamento dos tetos físico e } \\
\text { financeiro na Programação Pactuada e } \\
\text { Integrada }\end{array}$ \\
\hline & & $\begin{array}{l}\text { Financiamento e transferência dos } \\
\text { recursos federais - Rede de Atenção às } \\
\text { Urgências e Emergências }\end{array}$ \\
\hline & & $\begin{array}{l}\text { Aprova o remanejamento de recurso } \\
\text { financeiro de transferência do SUS do } \\
\text { Bloco de Custeio das Ações e Serviços } \\
\text { Públicos de Saúde de município, referente } \\
\text { a recurso dos tetos físico e financeiro } \\
\text { conforme Programação Pactuada e } \\
\text { Integrada da Assistência de Média e Alta } \\
\text { Complexidade (MAC Ambulatorial e } \\
\text { Hospitalar) }\end{array}$ \\
\hline & & $\begin{array}{l}\text { Aprova a solicitação de aumento de } \\
\text { recursos financeiros de Média e Alta } \\
\text { Complexidade Ambulatorial e Hospitalar } \\
\text { (MAC) de município. }\end{array}$ \\
\hline & & $\begin{array}{l}\text { Estratégicas e Compensação - FAEC para } \\
\text { o Componente Limite Financeiro Anual da } \\
\text { Assistência Ambulatorial e Hospitalar de } \\
\text { Média e Alta Complexidade - MAC dos } \\
\text { Estados, do Distrito Federal e dos } \\
\text { Municípios; }\end{array}$ \\
\hline & & Aprova limites financeiros \\
\hline
\end{tabular}

\section{Região de Saúde}

Aprova a alteração da especialidade da serviço. 


\begin{tabular}{|c|c|c|}
\hline & & $\begin{array}{l}\text { disponibilizados ao município, destinados } \\
\text { ao custeio dos procedimentos CIRúrgicos } \\
\text { eletivos, que referenciará Região de } \\
\text { Saúde. }\end{array}$ \\
\hline Governança & $\begin{array}{l}\text { Estratégias } \\
\text { governamentais } \\
\text { para fortalecer a } \\
\text { governança regional } \\
\text { e aperfeiçoar as } \\
\text { redes de } \\
\text { comunicação, } \\
\text { contribuindo para a } \\
\text { integralidade das } \\
\text { ações federativas. } \\
\text { Sustentação da } \\
\text { gestão } \\
\text { compartilhada. }\end{array}$ & $\begin{array}{l}\text { Aprova a Câmara Técnica de Comissão } \\
\text { Intergestores Regional } \\
\text { Homologa Coordenadora de Comissão } \\
\text { Intergestores Regional. }\end{array}$ \\
\hline
\end{tabular}

Fonte: Autoria própria, 2020

\section{DISCUSSÃO}

\subsection{PLANEJAMENTO REGIONAL EM SAÚDE}

O planejamento é um processo permanente e dinâmico, devendo contemplar também situações emergenciais equacionadas em curto prazo. Na área da saúde, o planejamento é de competência das três esferas de Governo e constitui a base para a execução, o acompanhamento, a avaliação, o controle e a gerência do sistema de saúde, pressupondo o conhecimento da realidade existente e dos instrumentos disponíveis e necessários para se atingir as metas propostas. 
De acordo com Santos (2017) a ausência do planejamento, prejudica a organização dos serviços de saúde, enfraquecendo a cooperação e coordenação da política de regionalização. Aliás, a Constituição Federal, em seu art. 176, determina ser o planejamento obrigatório para o Poder Público e indutor para o setor privado (BRASIL, 1988).

O processo de regionalização da saúde possibilita a alocação de serviços na rede de saúde, de forma a contemplar todos os níveis de saúde, conforme a necessidade dos indivíduos. Os documentos analisados na presente pesquisa demonstraram que o planejamento tem se tornado importante pauta nas agendas de discussão de gestores nas regiões de saúde.

Uma das consequências do planejamento é proporcionar o esclarecimento das responsabilidades das três esferas de governo, da definição da prestação e gestão dos serviços e do aporte dos recursos financeiros. Dessa forma, o processo de planejamento e orçamento deve ser indivisível. Assim, a Programação orçamentária em saúde é essencial, como parte integrante e detalhamento dos planos de saúde (BRASIL, 2011).

Segundo Duarte e outros colaboradores (2018) a organização do planejamento e orçamento do SUS é ascendente, integrado realizado de forma regionalizada, a partir do reconhecimento dos problemas de saúde de cada município, construído através da articulação entre entes autônomos, a fim de garantir qualidade de vida da população, mediante a organização dos serviços de saúde. $\mathrm{Na}$ prática o planejamento e organização das atividades de cada nível de direção do SUS, será ascendente, guiado pelas necessidades de saúde da população, mediante a organização do plano de saúde em cada jurisdição, onde seu financiamento está previsto na proposta orçamentaria (BRASIL, 1990).

O planejamento regional integrado estabelece a CIR como espaço de articulação, negociação e pactuação entre os entes signatários, permitindo identificação, definição de prioridades e de negociação de soluções para a organização de uma 
rede regional de ações e serviços de atenção à saúde integra e resolutiva de acordo com os princípios do SUS (BRASIL, 2011).

A CIR tem a importância de consolidar as políticas públicas em saúde, através do acompanhamento da Programação Pactuada Integrada, de forma a favorecer a construção do desenho regulatório, com definição de fluxos e protocolos com vista a qualificação do controle social e organização da gestão compartilhada de forma ascendente, planejada com definição dos recursos financeiros e administrativos que contribuam para a regionalização (BRASIL, 2011).

Os resultados da análise documental evidenciam que a CIR é um espaço com potencial para desenvolver a capacidade institucional, para o planejamento e a coordenação territorial regional, voltada à superação de interesses corporativos e criação de uma governança local baseada na cogestão e democratização da decisão e cooperação intergovernamental.

\subsection{ORGANIZAÇÃO DAS AÇÕES E SERVIÇOS DE ATENÇÃO À SAÚDE: REGIÃO DE SAÚDE.}

A análise das resoluções da CIR mostra que a organização da assistência à saúde é "palco" constante de discussão nas esferas federativas, evidenciando que as redes de atenção à saúde são o direcionamento para o trabalho de pactuação dentro das Comissões Intergestores (BRASIL, 2011).

A organização dos serviços de saúde deve estar contemplada nas regiões de saúde, que constituem espaço geográfico contínuo, incorporado por aglomerado de municípios, constituído de base territorial de planejamento da atenção à saúde, que resulta da região compartilhada do financiamento regional através da execução de serviços que visem a governança na região, através da cooperação entre os entes federativos; devem conter ações de atenção básica, atenção psicossocial, vigilância à saúde, urgência-emergência, atenção ambulatorial especializada e hospitalar (BRASIL, 2011). 
Para que ocorra a integração das ações e serviços públicos de saúde em rede regionalizada, é necessário que os entes federados trabalhem de forma integrada.

Essa agregação de serviços na região é necessária para garantir a integralidade do cuidado, mediante o fluxo de referência e contrarreferência, cabendo ao gestor de maior porte responder, na região, por serviços de maior complexidade, que exigem escala e outros componentes administrativos e tecnológicos, os quais poderão ser acessados por municípios de outros entes federados (ANDRADE; FRANCISCHETTI, 2019).

De acordo com Santos (2017) a cooperação entre as instâncias de pactuação no território como forma de organização dos espaços de atuação do SUS, é ponto chave dada a sua singularidade sanitária, tecnológica e financeira é fundamental na estruturação do SUS. Sem esse formato organizativo, o sistema de saúde não consegui prover a assistência de forma integral, igualitária e descentralizada.

Como forma de organizar e integra essa rede de serviços dentro do território, os ente signatários assumem a responsabilidade estabelecida no Contrato Organizativo de Ação Pública (COAP), com a finalidade de garantir as ações e serviços de saúde de forma regionalizada e hierarquizada, com definição de competência executiva, orçamentária, financeira e controle de avaliação definida entre Estados, Município e União, estabelecendo metas de saúde para custeio e investimento que garanta atendimento integral a população (BRASIL, 1990, 2010, 2011; SANTOS, 2017).

A decisão de qualificar a atenção e a gestão em saúde envolve aspectos técnicos, éticos e, culturais, implicando precipuamente o cumprimento do pacto político cooperativo entre as instâncias de gestão do sistema, expresso por uma "associação fina da técnica e da política", para garantir os investimentos e recursos necessários à mudança (BRASIL, 2010, 2011).

A solução está em inovar o processo de organização do sistema de saúde, reordenando ações e serviços no desenvolvimento das Redes Regionalizadas de 
Atenção à Saúde (RAS), para produzir impacto positivo nos indicadores de saúde da população.

O Pacto de Gestão do SUS estabelece a necessidade de desenhar RAS, organizadas nos territórios das regiões de saúde sendo este o espaço privilegiado de construção das responsabilidades pactuadas e permite a integração de políticas e programas por meio da ação conjunta das esferas federal, estadual e municipal (BRASIL, 2010).

O Decreto 7508/11, no capítulo II, define que o SUS deve ser formado por uma rede regionalizada e hierarquizada, e que suas regiões de saúde devem organizar-se para ofertar serviços de saúde articulados em níveis de complexidade crescente, com a finalidade de garantir a integralidade do cuidado e a assistência à saúde (BRASIL, 2001).

O Pacto estabeleceu o espaço regional como local privilegiado de construção das responsabilidades pactuadas, requerendo o cumprimento das responsabilidades assumidas e metas pactuadas, sendo cada esfera de governo corresponsável pela gestão do conjunto de políticas, com responsabilidades explicitadas (BRASIL, 2006).

Os resultados mostram claramente a organização dos serviços de saúde por redes de atenção e os acordos federativos para execução dos serviços, contemplando as necessidades das regiões de saúde. De acordo com Santos (2017) é necessário atuar de maneira integrada e sistêmica compartilhando competência de modo flexível, visando garantir acordo entre os entes federativos, que influenciem a saúde da população, promovendo a intersetorialidade, capaz de diminuir as desigualdades sociais.

RC: 97046

Disponível em: https://www.nucleodoconhecimento.com.br/tecnologia/comissaointergestores-regional 


\subsection{FEDERALISMO, COMISSÕES INTERGESTORES E 0 FINANCIAMENTO DOS SERVIÇOS DE SAÚDE.}

O federalismo é uma forma de organização do Estado que nasceu do equilíbrio dialético entre a centralização e a descentralização do poder político, correspondendo à necessidade de manutenção da unidade na diversidade, sem concentrar o poder em um único núcleo, nem tampouco pulverizá-lo (DOURADO; ELIAS, 2011).

Segundo Curvina (2017), o federalismo surgiu em 1787, com a Constituição dos Estados Unidos da América. Conforme a autora, o modelo do federalismo norteamericano foi copiado pelos demais países, convergindo, no todo ou em parte, para uma dualidade de competências, caracterizada pela coexistência de, no mínimo, duas esferas constitucionais de poder autônomo, atuando sobre um mesmo território e uma mesma população (MENICUCCI, 2019).

No Brasil, o federalismo partiu da existência de uma unidade com poder centralizado, distribuindo-o entre várias unidades (entes federados), sem eliminar o poder central. Esse poder delegado a Estados e Municípios é amparado constitucionalmente através das legislações federal, estadual e municipal. Um sistema de federalismo cooperativo, tanto para assuntos econômicos, como sociais e culturais, através de programas e financiamentos conjuntos, considerado por Viana et al (2008). como "flexibilidade institucional", busca de cooperação intergovernamental para alcançar fins comuns.

Barata (2004) convém assinalar que não há hierarquia na organização federal, porque a cada esfera de poder corresponde uma competência determinada, pressupondo autonomia dos entes federados. Embora o estudo do federalismo passe pelo exame das especificidades de cada Federação, há características comuns que representam os fundamentos do Estado federal. 
$\mathrm{Na}$ atual conjuntura histórica, em que os Estados nacionais têm o papel preponderante de promover o bem-estar social, há necessidade de colaboração mútua entre as esferas de governo, para a consecução dos objetivos sociais e econômicos, advindo da identificação de que a execução de determinadas funções públicas não pode ser atribuição exclusiva ou hegemônica de algum dos entes federados, pois implicam divisão de competência, cooperação e interesses comuns. Esse é o modelo predominante nos dias de hoje, denominado federalismo cooperativo (CURVINA, 2017).

De fato, a gestão de políticas públicas é fundamental para o desenvolvimento de metas e ações no âmbito socioeconômico que visem o bem-estar coletivo da população, mediante a cooperação nas três esferas de governo através da construção de processos decisórios e planejados (SOARES, 2018). Esses processos representam o "inerente dilema entre as negociações diretas dos governos locais e os incentivos promovidos pelas instancias centrais", advindos de problemas recorrentes representados pela descentralização e a centralização (DOURADO; ELIAS, 2011, p. 206).

Uma adesão permanente da gestão do SUS é o fortalecimento dos vínculos interfederativos, necessários à consolidação do sistema. A Lei Orgânica da Saúde (Lei 8.080/90), estabeleceu novas estratégias e instrumentos para a consolidação das redes de atenção à saúde, valorizando a construção de relações colaborativas entre os entes federados por meio do COAP e fortalecendo o papel de coordenação dos gestores estaduais e das comissões Intergestores (BRASIL, 1990).

De fato, a descentralização busca construir relações intergovernamentais na implementação de políticas públicas e reforça a importância do diálogo entre os governos subnacionais quanto do governo nacional na condução da política de saúde. Além de produzir expressivas mudanças no desenho institucional na organização governamental e no campo social com ênfase na comunicação e compartilhamento de responsabilidade entre os entes federais na gestão política e financeira dos sistemas locais de saúde, ampliando a cobertura e favorecendo o 
acesso da população a serviços e ações de saúde (MOREIRA; FERRÉ; ANDRADE, 2017).

É indiscutível que a descentralização esbarra na assimetria financeira e de gestão dos níveis de governo, na organização e gerenciamento da rede de serviços heterogênea e não integrada institucionalmente com impactos decorrentes do aparecimento de vários sistemas locais e isolados de serviços de saúde, bem como na fragmentação e desorganização dos serviços disponibilizados a comunidade (LEVCOVITZ et al, 2001; SANTOS et al, 2015). Um outro ponto importante ocasionado pela descentralização discutidos pelos autores relaciona-se ao distanciamento das instâncias governamentais responsável pelo financiamento da saúde (PINAFO et al, 2020).

A relação entre descentralização, eficiência e equidade está permeada por complexas redes de causalidade, contudo, as evidências existentes indicam que, em um país continental como o Brasil, constituído por diversidades espacial, desigualdades territoriais, os custos de distribuição, intermediação e controle superam largamente os ganhos de gestão de recursos, distribuição de bens e serviços conquistados pela administração centralizada (AFFONSO, 1985; LIMA et al, 2015).

De fato, a concentração geográfica de serviços de maior cumplicidade, às diferenças regionais entre as populações e condições político-institucionais dos entes federativos no Brasil, há necessidade e utilização dos recursos disponíveis, com compartilhamento de responsabilidade entre as esferas de gestão, a fim de conciliar interesses conflitantes de diferentes regiões, objetivando a construção de um modelo cooperativo e financeiro na prestação dos serviços de saúde (LIMA et al, 2012).

RC: 97046

Disponível em: https://www.nucleodoconhecimento.com.br/tecnologia/comissaointergestores-regional 


\subsection{GOVERNANÇA E AS COMISSÕES INTERGESTORES} REGIONAIS - CIR: CANAL DE NEGOCIAÇÃO E DECISÃO ENTRE GESTORES MUNICIPAIS E O ESTADO NO ÂMBITO DA REGIÃO DE SAÚDE.

As CIR/AL foram instituídas em 22 de agosto de 2011, e seu regimento as define como instâncias privilegiadas de negociação, articulação, proposição e pactuação quanto aos aspectos operacionais do SUS no âmbito da Região de Saúde, respeitadas as definições da Comissão Intergestores Bipartite (ClB), constituindo-se como espaço permanente de cogestão solidária e cooperativa no âmbito regional, a partir da identificação, de uma rede de serviços de atenção à saúde organizada, integrada e resolutiva, garantindo o aprimoramento e aplicação dos princípios do SUS (COSEMS/AL, 2014).

Compostas pelos Secretários Municipais de Saúde e pela representação da Secretaria de Estado da Saúde, que tem a prerrogativa de coordenar o processo de pactuação, suas decisões são tomadas por consenso, em conformidade com as disposições estabelecidas pelo Pacto pela Saúde.

No estado de Alagoas, mediante a aprovação do Plano Diretor de Regionalização (PDR), redefiniu-se o desenho territorial sanitário, reorganizado em duas Macrorregiões de Saúde, subdivididas em dez Regiões Sanitárias, sendo 06 (seis) na $1^{\text {a }}$ Macrorregião, com sede em Maceió, e 04 (quatro) na $2^{\underline{a}}$ Macrorregião, com sede no município de Arapiraca.

Com a missão de gerenciar a Política Regional de Saúde, a partir do conhecimento da realidade epidemiológica e socioeconômica do município, do território e da região, a CIR, coordena a construção da RAR, garantindo o acesso da população aos serviços de saúde, regulando, monitorando e avaliando as metas estabelecidas para os municípios. 
Objetivando aprofundar o caráter cooperativo das relações intergovernamentais estabelecidos pelo Pacto pela Saúde e de institucionalizar, no âmbito da gestão do SUS, um conjunto de ferramentas gerenciais e assistenciais, o Decreto 7.508/2011 traz a definição das regiões de saúde e das redes de atenção à saúde, cria o mapa da saúde, a Relação Nacional de Ações e Serviços de Saúde - RENASES a Relação Nacional de Medicamentos Essenciais - RENAME, e o COAP (BRASIL, 2011). Institui as instâncias de negociação e articulação intergovernamental que atuam em diversas escalas territoriais (nacional, estadual e regional).

Segundo a teoria habermasiana, a efetividade das demandas percebidas na esfera pública precisa de fluxos de comunicação e diálogo, ou seja, um modelo deliberativo de democracia. Na concepção republicana, o espaço público e político e a sociedade civil como sua infraestrutura, são pontos estratégicos de organização democrática e comunicativa. Tendo a função de garantir a força integradora e a autonomia democrática da prática de entendimento entre os sujeitos (HABERMAS, 1995).

Em condições estratégicas, os indivíduos tomam decisões que antecipam consequências de seus atos, escolhem instituições políticas, em uma palavra, agem politicamente. E a maneira como atuam desempenha um papel decisivo na obtenção e manutenção da democracia, de forma a abrir caminhos que possibilitem a comunicação, contribuindo para um bem maior, o direito à saúde.

Habermas (1995) do ponto de vista da teoria discursiva, a formação democrática da vontade legitima-se por meio dos pressupostos decisórios e comunicativos, que permitem através da racionalidade o uso público da razão de dialogar com as necessidades de saúde da população a fim de garantir processos justo e cooperativos.

O bom desenvolvimento cooperativo ocorridos por meio da CIR, contribui para a articulação e regulação das ações dentro dos territórios através da negociação compartilhada assumida pelos entes federados em uma perspectiva solidária (Lima, 
2012; Santos et al, 2014). Assim, o fortalecimento da governança em região de saúde pode aglutinar o que a descentralização, por si, fragmentou e superar os desafios à integração assistencial organizada nas regiões de saúde (LIMA et al, 2016).

Carvalho et al (1995), consideram que, em função do que foi estabelecido na Constituição Federal, os municípios desfrutam de autonomia política e administrativa para planejarem e gerirem seus sistemas locais de saúde. Por isso, a única maneira do Ministério e das Secretarias de Estado da Saúde interferirem na gestão municipal seria por meio de acordos e contratos livremente estabelecidos entre as partes.

Nas palavras de Noronha et al (2008), o SUS "parte de uma concepção ampla do direito à saúde e do papel do Estado na garantia desse direito, incorporando em sua estrutura institucional e decisória, espaços e instrumentos para democratização e compartilhamento da gestão do sistema de saúde".

Diante de tais características e do modelo federativo definido constitucionalmente na saúde, assume especial relevância o fortalecimento da gestão compartilhada e dos instrumentos que podem favorecê-la, entre eles.

O estudo permitiu alcançar diversas considerações acerca do tema, sem pretender, com isso esgotá-lo, dadas as limitações impostas pelo recorte da pesquisa ou mesmo pelo tipo de análise proposta pelo estudo.

\section{CONCLUSÃO}

Garantir acesso aos serviços de saúde, buscando a integralidade do cuidado exige uma organização sistêmica, advindas de pactos cooperativos ensejados no seio da governança federativa objetivando o fortalecimento da organização das regiões de saúde. Tendo as CIR como órgão importante na coordenação, organização e construção dos espaços de pactuação com vista a reconstrução e organização social. 
O aprendizado institucional, fruto da dinâmica de participação nas CIR, fortalece a gestão Intergestores e se apresenta como importante componente para a construção da rede regionalizada.

A presente pesquisa demonstra que o planejamento integral regional, a organização das ações e serviços, o financiamento e a governança regional, são elementos essenciais no processo de regionalização, alcançados através das deliberações da CIR, como também outros pontos pactuados nas reuniões, conforme descrito nas resoluções, tendo como foco principal a oferta de serviços de saúde disponível à população.

A cooperação tende a favorecer aos municípios integrantes de uma região, pois permite a otimização de recursos, a utilização solidária dos meios dispersos entre os entes federados, e a garantia de rentabilidade para os municípios com capacidade de atendimento, restando claro que as CIR/AL são verdadeiro espaço local de pactuação e articulação interfederativa.

\section{REFERÊNCIAS}

AFFONSO, Rui de Brito Álvarez. SILVA, Pedro Luiz Barros. (Org). A federação em perspectiva: ensaios selecionados. São Paulo 10 (3) Edições Fundap; 1995 [acesso em 3 jul 2020]. Disponível em:https://www.seade.gov.br/wpcontent/uploads/2014/07/v10n3.pdf

ANDRADE, Laurielle de Souza.; FRANCISCHETTI, leda. Referência e contrarreferência compreensões e práticas. Sal. \& Transf. Soc. Florianópolis, v. 10, n. 1/2/3, p. 54-63. 2019 [acesso em 13 jul. 2021]. Disponível em: file://C:/Users/nadja/Dropbox/My\%20PC\%20(LAPTOP-

EA4SVGFV)/Downloads/5281-22616-1-PB.pdf.

BARATA, Luiz Roberto Barradas. TANAKA, Oswaldo Yoshimi. MENDES, José Dínio Vaz. Por um processo de descentralização que consolide os princípios do Sistema Único de Saúde. Epidemiologia e Serviços de Saúde, Brasília, 13 (1) 15- 
24. 2004 [acesso em 02 jun 2020]. Disponível em: http://scielo.iec.gov.br/pdf/ess/v13n1/v13n1a03.pdf

BRASIL. Conselho Nacional de Secretários de Saúde. Legislação Estruturante do SUS/CONASS. Brasília, 2011. 534. [acesso em 25 jul, 2020]. Disponível em: http://bvsms.saude.gov.br/bvs/publicacoes/para_entender_gestao_sus_v13.pdf

BRASIL. Constituição (1988). Constituição da República Federativa do Brasil. promulgada em 5 de outubro de 1988. Brasília, DF: Senado Federal;1988 [acesso $\begin{array}{lllll}\text { em } & 10 & \text { mai } & \text { 2020]. }\end{array}$ https://www2.senado.leg.br/bdst/bitstream/handle/id/518231/CF88_Livro_EC91_201 6.pdf

BRASIL. Decreto n. 7.508, de 28 de junho de 2011. Regulamenta a Lei n. 8.080, de 19 de setembro de 1990, para dispor sobre a organização do Sistema único de Saúde - SUS, o planejamento da saúde, a assistência à saúde e a articulação interfederativa, e dá outras providencias. Diário Oficial da União, Poder Executivo, Brasília, DF, 29 jun. 2011. Seção 1, p 1. [acesso em 10 fev 2020]. Disponível em http://www.planalto.gov.br/ccivil_03/_Ato2011-2014/2011/Decreto/D7508.htm.

BRASIL. Lei o 8.080, de 19 de setembro de 1990. Lei Orgânica da Saúde. Dispõe sobre as condições para a promoção, proteção e recuperação da saúde, a organização e o funcionamento dos serviços correspondentes e dá outras providências. Brasília, set. 1990. [acesso em 23 abri 2020]. Disponível em: http://www.planalto.gov.br/ccivil_03/leis//8080.htm

BRASIL. Ministério da Saúde. Portaria 4.279, de 30 de dezembro de 2010. Estabelece diretrizes para a organização da Rede de Atenção à Saúde no âmbito do Sistema Único de Saúde (SUS). Diário Oficial da União 31 dez. 2011[acesso em 27 jul 2020].

https://bvsms.saude.gov.br/bvs/saudelegis/gm/2010/prt4279_30_12_2010.html 
BRASIL. Ministério da Saúde. Secretaria de Atenção à Saúde. Departamento de Regulação, Avaliação e Controle de Sistemas. Diretrizes para a programação pactuada e integrada da assistência à saúde. Brasília. 2006. [acesso em: 27 jul 2020].

Disponível

em: http://bvsms.saude.gov.br/bvs/publicacoes/DiretrizesProgPactuadalntegAssistSaude. pdf

BRASIL. Ministério da Saúde. Secretaria de Gestão e Participativa. Contrato Organizativo da Ação Pública da Saúde. Brasília. 2011 [cesso 30 jul 2020]. Disponível em: http://bvsms.saude.gov.br/bvs/publicacoes/contrato_organizativo_acao_publica_sau de.pdf

BRASIL. Resolução oo 1 setembro de 2011. Gabinete do Ministério da Saúde. Comissão Intergestores Tripartite. Brasília, [citado 07 Jul. 2020]. Disponível em: https://bvsms.saude.gov.br/bvs/saudelegis/cit/2011/res0001_29_09_2011.html

CARVALHO, Guido Ivan. SANTOS, Lenir. Comentários à lei orgânica da saúde: sistema único de saúde. São Paulo: Ed. Hucitec, 1995

CONSELHO DE SECRETÁRIOS MUNICIPAIS DE ALAGOAS. O papel dos gestores de saúde nas comissões Intergestores regionais. Maceió, 2014 [acesso em 12 abr 2020]. Disponível em: http://www.cosemsal.org/old/public/documentos/manual-azul---o-papel-dos-gestoresde-saude.pdf

CURVINA, Ana Cristina Carvalho. A regionalização da saúde no federalismo brasileiro. Cad. Ibero-Amer. Dir. Sanit., Brasília, 6(2):42-57, abr./jun, 2017. [acesso em 13 fev 2020]. Disponível em: http://dx.doi.org/10.17566/ciads.v6i2.385

DOURADO, Daniel de Araújo.; ELIAS, Paulo Eduardo Mangeon. Regionalização e dinâmica política do federalismo sanitário brasileiro. Rev. Saúde Pública. São 
Paulo, v. 45, n. 1, p. 204-11. 2011. [acesso em 05 jul. 2021]. Disponível em: https://www.scielo.br/j/rsp/a/bCWB3sWTXQLXWjjFkcWwgLt/?format=pdf\&lang=pt

DUARTE, Ligia Schiavon.; MENDES, Áquilas Nogueira.; LOUVISONA, Marília, Cristina Prado. O processo de regionalização do SUS e a autonomia municipal no uso dos recursos financeiros: uma análise do estado de São Paulo (2009-2014). Saúde Debate, Rio de Janeiro, v. 42, n. 116, p. 25-37. 2018. [acesso em 10 jul 2020].

https://www.scielo.br/j/sdeb/a/gcPyhjjWdrqZcG9V4nYhPBd/?format=pdf\&lang=pt.

HABERMAS, Jurgen. Três Modelos Normativos de Democracia. Cadernos da Escola do Legislativo, Belo Horizonte, 3 (3)105-122, jan.-jun., 1995.

LEVCOVITZ, Eduardo. LIMA, Luciana Dias de. MACHADO, Cristiane. Vieira. Política de saúde nos anos 90: relações intergovernamentais e o papel das Normas Operacionais Básica. Ciência e Saúde Coletiva, Rio de Janeiro, 6, (2) 269-291, 2001 [acesso em 10 jul 2020]. Disponível em: https://www.scielo.br/pdf/csc/v6n2/7003.pdf.

LIMA, Luciana Dias de. et al. Regionalização e acesso à saúde nos estados brasileiros: condicionantes históricos e político-institucionais. Ciência e Saúde Coletiva, Rio de Janeiro, 17 (11) 2881-2892, 2012 [acesso 10 jun 2020]. Disponível em: https://www.scielo.br/pdf/csc/v17n11/v17n11a04.pdf

LIMA, Luciana Dias de.; ALBUQUERQUE, Mariana Vercesi.; SCATENA, João Henrique Gurtler. Quem governa e como se governam as regiões e redes de atenção à saúde no Brasil? Contribuições para o estudo da governança regional na saúde. Novos Caminhos, n. 8. 2016. [acesso em 29 fev 2020]. Disponível: https://www.resbr.net.br/wp-content/uploads/2016/02/Novos-Caminhos-8.pdf.

LIMA, Luciana Dias de. et al. Descentralização e regionalização: dinâmica e condicionamento da implantação do pacto pela saúde no Brasil. Ciência \& Saúde 
Coletiva, n. 17, v. 7, p. 1903-1914, 2012. [acesso em 29 fev. 2020]. Disponível em: https://www.scielo.br/j/csc/a/FyqLwWmbv8WQs8BPW8scpTt/?lang=pt

MENICUCCI, Telma Maria Gonçalves. Regionalização no federalismo brasileiro. Cad. Saúde Pública 2019; 35 Sup 2: e00078419. [acesso em 29 fev 2020]. Disponível: https://www.scielosp.org/article/csp/2019.v35suppl2/e00078419/pt/

MINAYO, Maria Cecília de Souza. O desafio do conhecimento. Pesquisa qualitativa em saúde; $12^{\underline{a}}$ ed; São Paulo. Hucitec. 2010. 407p. ISBN 978-85-271-0181-3.

MOREIRA, Laura Monteiro de.; FERRÉ, Felipe.; ANDRADE, Eli lola Gurgel. Financiamento, descentralização e regionalização: transferências federais e as redes de atenção em Minas Gerais, Brasil. Ciência \& Saúde Coletiva, n 22, v. 4, p. 1245-1256, 2017. [acesso em 21 ago 2021]. Disponível em: https://www.scielosp.org/pdf/csc/2017.v22n4/1245-1256/pt.

NORONHA, José Carvalho de. LIMA, Luciana. Dias de. MACHADO, Cristiane Vieira. O Sistema Único de Saúde: SUS. In: Giovanella L. et al. (Org.). Políticas e sistemas de saúde no Brasil. Rio de Janeiro: Fiocruz, 2008. p. 365-394.

PINAFO, Elisangela. et al. Problemas e estratégias de gestão do SUS: a vulnerabilidade dos municípios de pequeno porte. Ciência \& Saúde Coletiva, n2. 25, v. 5, p. 1619-1628, 2020 [acesso em 21 ago 2021]. Disponível em: https://scielosp.org/pdf/csc/2020.v25n5/1619-1628/pt

SANTOS, Adriano Maia dos. GIOVANELLA, Ligia. Governança regional: estratégias e disputas para gestão em saúde. Revista de Saúde Pública, São Paulo, 48 (4) 622-631, 2014[acesso em 10 jun 2020]. Disponível em: https://www.resbr.net.br/wpcontent/uploads/historico/governan\%C3\%A7a_regional.pdf

SANTOS, Lenir. CAMPOS, Gastão Wagner de Souza. SUS Brasil: a região de saúde como caminho saúde e Sociedade, São Paulo, 24 (2) 438-446, 2015 
[acesso

em

10

jul

2020].

Disponível

em:

https://www.scielo.br/pdf/sausoc/v24n2/0104-1290-sausoc-24-02-00438.pdf

SANTOS, Lenir. Região de saúde e suas redes de atenção: modelo organizativosistêmico do SUS. Ciência \& Saúde Coletiva, 22(4):1281-1289, 2017. [acesso em 29 jul, 2020]. Disponível em: https://www.scielosp.org/pdf/csc/2017.v22n4/1281$1289 / \mathrm{pt}$

SOARES, Marcia Miranda. MACHADO, José Ângelo. Federalismo e políticas públicas. Brasília: Enap, 2018. 112. [acesso em: 29 fev 2020]. ISBN: 978-85-2560081-3Disponível

em: https://repositorio.enap.gov.br/bitstream/1/3331/1/Livro_Federalismo\%20e\%20Pol\% C3\%ADticas\%20P\%C3\%BAblicas.pdf.

VIANA, Ana Luiza D’Ávila. LIMA, Luciana Dias. OLIVEIRA, Roberta. Gondim de. Descentralização e federalismo: a política de saúde em novo contexto - lições do caso brasileiro. Ciência e Saúde coletiva. 2002 Jul; 7 (3):493-507. [acesso em 5 mai 2020]. Disponível em: https://www.scielo.br/pdf/csc/v7n3/13027.pdf

VIANA, Ana Luiza D' Ávila. et al. Novas Perspectivas para a regionalização da saúde; São Paulo em perspectiva, 22 (1) 92-106, jan/jun.2008 [acesso em 7 jun 2020].

Disponível

em:

http://produtos.seade.gov.br/produtos/spp/v22n01/v22n01_07.pdf

WAGNER, Gastão. Efeitos paradoxais da descentralização do Sistema Único de

Saúde do Brasil; In: Fleury S. (Org.). Democracia, descentralização e desenvolvimento: Brasil e Espanha. Rio de Janeiro: FGV, 2006. 417-442. Disponível em https://www.scielo.br/pdf/csc/v17n11/v17n11a04.pdf.

Enviado: Março, 2021.

Aprovado: Setembro, 2021. 